\title{
Influence of modified biopolymers on thermal properties and biodegradation processes of carboxylated nitrile-butadiene (XNBR) nanocomposities
}

\author{
M. Prochon ${ }^{1}$
}

Received: 30 August 2018 / Accepted: 15 January 2020 / Published online: 12 February 2020

(c) The Author(s) 2020

\begin{abstract}
The presented study includes a comparison of the effect of fillers used in carboxylated nitrile butadiene rubber XNBR on the properties of the obtained polymer materials. Fillers used in this study originated from the tanning industry waste: cattle hair keratin, enzymatic hydrolyzate of cattle hair keratin and condensate of enzymatic hydrolyzate of cattle hair keratin. The use of commonly found in nature phyllosilicates allows to obtain nanocomposites. That is why in the presented study we used different mass fraction of layered silicate-montmorillonite. The dispersion of silicates in polymer matrices can be influenced by their physical and chemical modifications that lead to changes in the properties of the polymer matrices themselves. In the presented study the kinetics of vulcanization of elastomer blends was investigated, and the obtained XNBR rubber vulcanizates were analyzed for mechanical, optical, rheological, thermal analysis and their resistance to accelerated thermo-oxidative aging $(S)$ and susceptibility to biodegrade were tested. The produced elastomer composites may be used in the rubber industry in the assortment of various types of washers, elastomer seals or conveyor belts-materials that often work under elevated temperature conditions. Therefore, it seems advisable to understand the thermal properties of this type of materials, eg for suitability in real conditions. Therefore, Thermogravimetry (TG), Differential Scanning Calorimetry (DSC), Oxygen Index (IO) analyzes have been carried out, showing that different mechanisms of decomposition occur in layers of fiber-enriched polymer composites than unrecoverable ones. The modified keratin also slightly decreases the glass transition temperature. In addition, the presence of a modified keratin in the XNBR elastomer structure increases the composites compliance with the biodegradation process.
\end{abstract}

Keywords Thermal analysis $\cdot$ Biopolymers $\cdot$ Elastomers $\cdot$ Keratin $\cdot$ Protein $\cdot$ Biodegradation

\section{Introduction}

In recent years, the use of natural additives in polymer materials has become very fashionable—especially synthetic, like carboxylated acrylonitrile-butadiene rubber [1-4]. We deal with all kinds of biopolymers since 2002. The biopolimers which we are using in our investigations are keratin, collagen wastes of tanning industry, as well as bird feathers or potato protein which also are waste [5-7]. A small part of waste, from tannery or poultry industry, is used to produce,

M. Prochon

miroslawa.prochon@p.lodz.pl

1 Faculty of Chemistry, Institute of Polymers and Dye Technology, Lodz University of Technology, Stefanowskiego Street 12/16, 90-924 Lodz, Poland for example biogas or harmful animal feed. This feed is currently locked under Directive of the European Union [8]. Much of the rest of the waste is stored at landfills.

That is why we are still looking for solutions in which the keratin derived for example from tannery, poultry waste, will find other uses.

Keratin has proven itself as an additive flame retardant in specific conditions. After placing it into a butadiene-acrylonitrile matrix as filler, it resulted in the vulcanizates showing to be self-quenching during combustion [9].

Obtaining nowadays materials that would exhibit good mechanical properties simultaneously with good thermal stability and susceptibility to undergo biodegradation in the environment is extremely difficult. Synthetic rubber is a material that degrades difficultly, is hard and brittle after cross-linking only at very low temperatures, but at temperatures of use, it exhibits elastic deformation. Recently, a 
Fig. 1 Keratin cattle hair washed and dried photograph (a); powdered keratin cattle hair photo (b); keratin cattle hair SEM, magnification $50000 \times$ (c); enzymatic hydrolyzate of keratin SEM, magnification $50000 \times(\mathbf{d})$, Condensate of enzymatic hydrolyzate of keratin SEM, magnification $50000 \times$ (e); a, b photographs of IPDT (Institute of Polymer and Dye Technology); c-e SEM photographs were taken in Institute of High Pressure Physics of the Polish Academy of Sciences
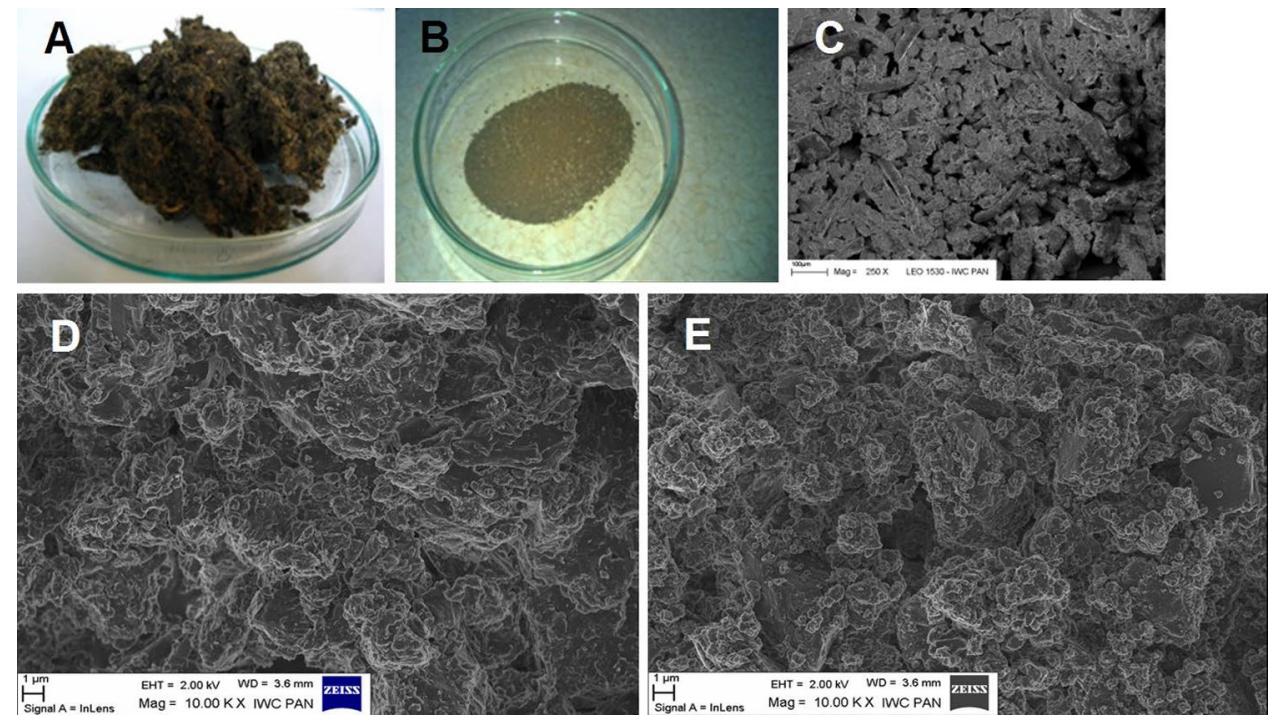

rapid development of manufacturing new polymeric materials such as polymer nanocomposites has been observed [10-15]. The reduction in the size of compound particles incorporated into a polymeric matrix from micrometers to nanometers makes it possible to obtain new composites with often better properties.

Many solutions are considered to achieve the desired properties of hardened rubber. One solution is to use fillers coming from the so-called aftermarket, i.e., being waste. Such waste can come from the tanning industry and large amounts of unused keratin [5, 16]. Keratin due to the presence in its structure of $15 \%$ of the nitrogen can act as a flame retardant-flame limiting factor. Its introduction into the structure of the elastomer should not only affect the improvement of the thermal stability of the obtained materials but should also promote cross-linking processes and increase resistance of the elastomer to thermo-oxidative degradation processes of the composites [7]. Furthermore, on the basis of differential scanning calorimetry (DSC) and TGA, it is known that water-insoluble amino acids derived from keratin such as bird feathers have antioxidant properties. [17, 18].
It aims to bring about a reduction in flexibility and increase the mechanical strength, while retaining the biodegradable character of the composite $[19,20]$. In the case of polymers as structural materials, valuable property is the introduction keratins as a filler, resulting in lower density of the composite-the finished product, with the consequent reduction in mass of the material [21, 22]. This leads to mutual interactions, which as a consequence improve mechanical strength, hardness and resistance to thermal aging [23, 24]. In recent times, the term of "Green Chemistry" gives a lot of emphasis on the reduction or elimination of waste during the various chemical processes and also seeks to limit the use of hazardous substances. Hence, the use of keratin derived from waste seems to be the right solution to reduce the amount of waste, and recycling. Composites containing natural polymers such as keratin, often have a high ability to biodegrade, i.e., that exhibit improved assimilation by microorganisms leading to disintegration of the material after its service use [17].

Organically modified montmorillonites (MMT) were widely used to obtain nanocomposites with diverse properties $[25,26]$. Through the process of intercalation, which is
Fig. 2 Scheme of keratin enzymatic hydrolysis (a); scheme of keratin condensation reaction (b)

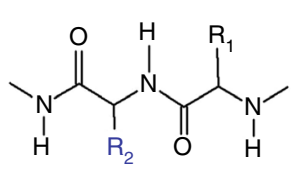

Fragment of protein

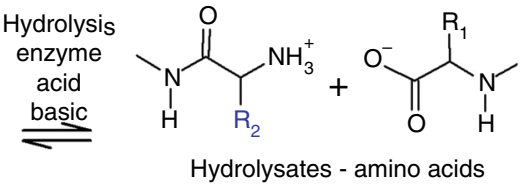

Hydrolysates - amino acids

A

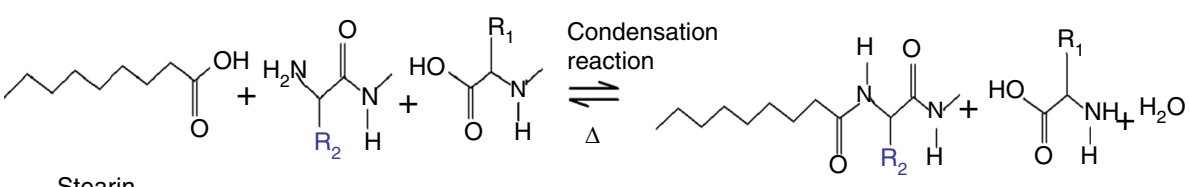

Stearin

B

Amino acid, dipeptide, oligopeptides
Condensate of hydrolysate and stearin 
Table 1 Content of rubber blends

\begin{tabular}{lcclcc}
\hline Sample & Keratin $(\mathrm{K})$ & $\begin{array}{l}\text { Enzymatic hydrolysis } \\
\text { of keratin }(\mathrm{H})\end{array}$ & $\begin{array}{l}\text { Condensate of } \\
\text { keratin }(\mathrm{A})\end{array}$ & $\begin{array}{l}\text { Montmorillon- } \\
\text { ite }(\mathrm{M})\end{array}$ & $\begin{array}{l}\text { Technical } \\
\text { stearin }\end{array}$ \\
\hline XM5 & 0 & 0 & 0 & 5 & 2 \\
XMK5 & 5 & 0 & 0 & 5 & 2 \\
XMH5 & 0 & 5 & 0 & 5 & 2 \\
XMA5 & 0 & 0 & 5 & 5 & 0 \\
XM10 & 0 & 0 & 0 & 10 & 2 \\
XMK10 & 10 & 0 & 0 & 10 & 2 \\
XMH10 & 0 & 10 & 0 & 10 & 2 \\
XMA10 & 0 & 0 & 10 & 10 & 0 \\
\hline
\end{tabular}

Other components: XNBR Krynac X7.50, 6.7\%—carboxylic group, 27\%-acrylonitrile mers-100/phr, $\mathrm{ZnO}$ (zinc oxide)—5/phr; S (Sulfur)—2.5/phr; MBTS (dibenzothiazyl disulfide)—1.5/phr significantly facilitated between montmorillonite and polar particles of non-polar solvents, an essential role of MMT is, for example, preventing the access of non-polar solvents while limiting the elimination of anti-aging agents on the surface or in the interlayer regions of this type of composites. At that time, the resistance against cracking of the ozone layer increases and, consequently, prolonged life-time effectiveness, which is also confirmed by thermal phenomena [differential thermal analysis (DTA), thermogravimetry (TG)] occurring at high temperatures for the intercalated compound. In other studies [27] it was observed that the thermal stability and flammability of the tested nanocomposites depend both on the structure of the rubber network and the type of montmorillonite. Nanoadditives (aluminosilicates) are used to reduce the flammability of cross-linked NBR butadiene nitrile rubber and significantly reduce its fire hazard.

This study presents the findings concerning the effect of keratin and modified keratin (enzymatic hydrolyzate of keratin and condensate of the enzymatic hydrolyzate of keratin with technical stearin), derived from environmentally polluting wastes from the tanning industry, on the thermal properties and biodegradation process of carboxylated acrylonitrile-butadiene rubber (XNBR) additionally containing montmorillonite in two mass fractions.

\section{Experimental}

\section{Materials}

Under investigation there was a carboxylated acrylonitrile-butadiene rubber, XNBR, (Krynac X7.50, producer Bayer AG, Leverkusen, Germany, 6.7\%—carboxylic group, 27\%-acrylonitrile mers, Mooney's viscosity: ML $(1+4)$ $\left.100{ }^{\circ} \mathrm{C} 47 \pm 5 \mathrm{MU}\right)$ cross-linked with the use of rhombic sulfur $\mathrm{S}_{8}$ (density $2.07 \mathrm{~g} \mathrm{~cm}^{-3}$, product of Chemical Company Siarkopol Tarnobrzeg Sp. z o.o., Poland) using mercaptobenzothiazole disulfide (MBTS) as an accelerator (POCH Gliwice, Poland). $\mathrm{ZnO}$ is a product from Huta Oława, Poland; first class, surface area $5-7 \mathrm{~m}^{2} \mathrm{~g}^{-1}$ and particle size $0.1-0.9 \mu \mathrm{m}$ ( $\mathrm{ZnO}$ - activator of cross-linking porcess). Technical stearin as a plasticizer from TorimexChemicals Ltd. Sp. z o.o. Poland. Montmorillonite Clay MMT (Nanoclay, hydrophilic bentonite, Sigma-Aldrich Co., USA), was incorporated into XNBR blend in a quantity of 5 or 10 phr. Keratin cattle hair $(\mathrm{K})$ was recovered from Kalisz Tannery Plant (Poland). Keratin cattle hair was separated from the tannery effluents in the Kalisz Tannery Company (Poland).

\section{Keratin modification}

Keratin in the first step was washed with water, dried and milled (Cryogenic mill MM400, Retsch GmbH, Germany) (Fig. 1a-c). The obtained powder was sieved through a screen with a mesh diameter of $0.1 \mathrm{~mm}$. Keratin in the next step was subjected to enzymatic hydrolysis and condensation reaction. The first enzymatic hydrolysis reaction took place in two stages, $88 \%$ and $82 \%$, respectively. Parameters of the two-stage enzymatic hydrolysis are as follows: first step: $\left(0.25 \mathrm{M} \mathrm{NaOH}\right.$, at $85{ }^{\circ} \mathrm{C}$, reaction time $2.5 \mathrm{~h}$, neutralization to $\mathrm{pH}=9-1 \mathrm{M} \mathrm{H}_{2} \mathrm{SO}_{4}$ ), second step: [application of proteolitic enzyme-Novo Unhairing Enzyme NUE 12 MP (Novozymes Biopharma Sweden)], at $50{ }^{\circ} \mathrm{C}$, for $3 \mathrm{~h}$, drying at $50{ }^{\circ} \mathrm{C}$, (Fig. 2a). The second condensation reaction proceeded using previously prepared enzymatic hydrolysate of keratin and technical stearin in the ratio of reactants of $5: 1$, at $60-65^{\circ} \mathrm{C}$, for $1.5 \mathrm{~h}$ (Fig. 2b). Both obtained products (Fig. 1d-e) were introduced as fillers to an elastomeric matrix after drying (Binder $\mathrm{GmbH}$ 07-30141 with circulating air, Tuttlingen, Germany) and milling (as above MM400). 


\section{Preparation of rubber blends}

Rubber mixtures were prepared with the use of a laboratory rolling mill (Mixing mill Bridge, Germany) with roll dimensions: $D=150 \mathrm{~mm}, L=300 \mathrm{~mm}$ at room temperature. The rotational speed of the front roll was $20 \mathrm{rpm}$, and the friction ratio was 1.15 . The montmorillonite clay $(\mathrm{M})$ and modified keratin were thermally stabilized at $50{ }^{\circ} \mathrm{C}$ for $3 \mathrm{~h}$ prior (Binder 07-30141) to incorporation into the elastomeric mixtures. Subsequently, the materials were cured between electrically heated press shelves at $150{ }^{\circ} \mathrm{C}$ for optimal vulcanization time $\tau_{90}$, determined according to the standard PN-ISO 3417:1994 by means of a WG-02 vulcameter with an oscillating rotor, the oscillation angle of the rotor was $3^{\circ}$, and the frequency of oscillation $1.7 \pm 0.1 \mathrm{~Hz}$. The vulcanization kinetics was tested using a vulkometer WG-02 (ZACH METALCHEM, Gliwice, Poland). For the mechanical tests, a steel blank (Strip cutter for rubber, Zwick/Roell, Germany) was cut with a $4 \mathrm{~mm}$ wide paddle-shaped nanocomposite sample, the width of the measuring section and the length of a paddle of $75 \mathrm{~mm}$. (Table 1).

\section{Methods of testing}

Below is the scope of research on XNBR vulcanizates containing modified biopolymers and montmorillonite obtained.

The vulcanization cross-linking density was determined by equilibrium swelling, according to the PN-ISO 817 : 2001/ap1: 2002 standard using the Flory-Rehner formula (1) [28] for interaction parameters elastomer-solvent defined formula $\mu_{0}=0.487, \beta=0.228$ means volume fraction of elastomer in the swollen gel.

$v_{\mathrm{e}}^{\mathrm{r}}=-\left[\ln \left(1-v_{\mathrm{r}}\right)+v_{\mathrm{r}}+\mu v_{\mathrm{r}}^{2}\right] /\left[v_{0}\left(v_{\mathrm{r}}^{1 / 3}-2 v_{\mathrm{r}} / f\right)\right]$

where $\nu_{\mathrm{e}}^{\mathrm{r}}$-the concentration of effective chains in a solvent (toluene or toluene and ammonia) $\left(\mathrm{mol} \mathrm{cm}{ }^{-3}\right), \nu_{\mathrm{r}}$-the volume of rubber in swollen gel, network capability is $4, v_{0}-$ molar volume of the solvent $\left(\mathrm{mol} \mathrm{cm}^{-3}\right)$.
Mechanical properties: tensile strength $\left(\mathrm{TS}_{\mathrm{b}} / \mathrm{MPa}\right)$ and elongation at break $\left(E_{\mathrm{b}} / \%\right)$ were determined according to the standard PN-ISO 37:1998 using the tensile testing machine Zwick 1442, 1435 (Zwick/Roell GmbH Germany). The initial force used in the measurement was $0.1 \mathrm{~N}$, test speed $500 \mathrm{~mm} \mathrm{~min}^{-1}$. Five measurements were made in one series, taking into account the critical dimension CD. Hardness determination was carried out using the Shore method in accordance with the PN-80/C-04238 standard. The hardness of rubber was measured with the use of an electronic hardness tester, type A from producer Zwick/Roell, pressure $12.5 \mathrm{~N}$

The thermal stability of vulcanizates determined by analyzer TGA/DSC (Mettler Toledo, Switzerland) is calibrated using standard pattern (indium, zinc) samples were heated at $10{ }^{\circ} \mathrm{C} \mathrm{min}-1$ in a stream of inert gas (argon) flow rate of $60 \mathrm{~cm}^{3} \mathrm{~min}^{-1}$ in the temperature range $25-800{ }^{\circ} \mathrm{C}$. The samples used for the tests weighed $90 \mathrm{mg}$.

The effect of heat and the range of the glass transition temperature were determined with a differential scanning calorimeter DSC (Mettler Toledo); measurement was carried out in a temperature range of $-80 \div+150{ }^{\circ} \mathrm{C}$, heating rate $10{ }^{\circ} \mathrm{C} \mathrm{min}-1$.

The combustibility of composites was determined using the oxygen index method (OI), according to PN-ISO 4589-2, using a self-construction apparatus [6], and on the basis of flammability measurement in the air, using samples of the same dimensions $(50 \times 10 \times 4 \mathrm{~mm})$ as in the case of an oxygen index. The tests were carried out with constant nitrogen flow rate of $400 \mathrm{~L} \mathrm{~h}^{-1}$, the oxygen flow was selected so that the sample tested was totally burned, including flame decay, within $t=180 \mathrm{~s}$. The sample top was ignited for $15 \mathrm{~s}$ by means of a gas burner using a propane-butane mixture [27].

The resistance to thermal aging was investigated according to the standard PN-88/C-04207, (Binder GmbH, Germany). The principle of determination consists in exposing an unstressed sample to the action of circulating air at a temperature of $70^{\circ} \mathrm{C}$ for $168 \mathrm{~h}$. Tensile strength and elongation at break of vulcanizates were measured before and after the
Table 2 The effect of keratin and its modification on rheometric, cross-linking density, mechanical properties and hardness of carboxylated acrylonitrile-butadiene XNBR rubber mixes and vulcanizates

\begin{tabular}{lllllllll}
\hline Composites & $L_{\mathrm{L}} / \mathrm{dNm}$ & $\Delta L / \mathrm{dNm}$ & $\tau_{0.2} / \mathrm{min}$ & $\tau_{90} / \mathrm{min}$ & $V_{\mathrm{T}} / \mathrm{mol} / \mathrm{dm}^{3}$ & $\mathrm{TS}_{\mathrm{b}} / \mathrm{MPa}$ & $E_{\mathrm{b}} / \%$ & $\mathrm{H} /{ }^{\circ} \mathrm{Sh}$ \\
\hline XM5 & $11 \pm 0.2$ & $107 \pm 0.2$ & $11 \pm 0.6$ & $108 \pm 1.1$ & $1.196 \pm 0.023$ & $12.60 \pm 0.11$ & $253 \pm 4.1$ & $47 \pm 2.0$ \\
XMK5 & $13 \pm 0.1$ & $111 \pm 0.3$ & $13 \pm 0.5$ & $113 \pm \mathrm{i} .4$ & $1.372 \pm 0.012$ & $13.08 \pm 0.09$ & $289 \pm 5.3$ & $64 \pm 1.1$ \\
XMH5 & $13 \pm 0.1$ & $109 \pm 0.2$ & $13 \pm 0.3$ & $112 \pm 0.9$ & $1.352 \pm 0.019$ & $14.26 \pm 0.20$ & $272 \pm 2.2$ & $65 \pm 1.2$ \\
XMA5 & $12 \pm 0.1$ & $110 \pm 0.3$ & $12 \pm 0.3$ & $112 \pm 1.1$ & $1.366 \pm 0.033$ & $14.70 \pm 0.18$ & $272 \pm 3.3$ & $66 \pm 1.0$ \\
XM10 & $13 \pm 0.4$ & $108 \pm 0.4$ & $13 \pm 0.4$ & $110 \pm 1.5$ & $1.474 \pm 0.027$ & $12.70 \pm 0.08$ & $251 \pm 5.6$ & $54 \pm 1.3$ \\
XMK10 & $14 \pm 0.3$ & $115 \pm 0.1$ & $15 \pm 0.4$ & $118 \pm 0.8$ & $1.510 \pm 0.022$ & $13.19 \pm 0.13$ & $278 \pm 3.0$ & $66 \pm 1.0$ \\
XMH10 & $14 \pm 0.4$ & $111 \pm 0.1$ & $14 \pm 0.1$ & $111 \pm 0.7$ & $1.711 \pm 0.014$ & $13.36 \pm 0.10$ & $267 \pm 5.4$ & $68 \pm 1.1$ \\
XMA10 & $14 \pm 0.2$ & $111 \pm 0.2$ & $14 \pm 0.1$ & $113 \pm 0.9$ & $1.954 \pm 0.017$ & $13.61 \pm 0.09$ & $272 \pm 4.2$ & $70 \pm 1.1$ \\
\hline
\end{tabular}

$L_{\mathrm{L}}-$ minimum of torque moment, $\Delta L$ - the increase of torque moment, $\left(\Delta L=L_{\mathrm{H}}-L_{\mathrm{L}}\right), L_{\mathrm{H}}$-maximum of torque moment, $\tau_{0.2}$-score time, $\tau_{90}$-time of vulcanization, $V_{\mathrm{T}}$-cross-linking density determined from equilibrium swelling in the toluene $10^{-4}, \mathrm{TS}_{\mathrm{b}}$ - tensile of strength, $E_{\mathrm{b}}$ - elongation at a break, $H$-hardness 


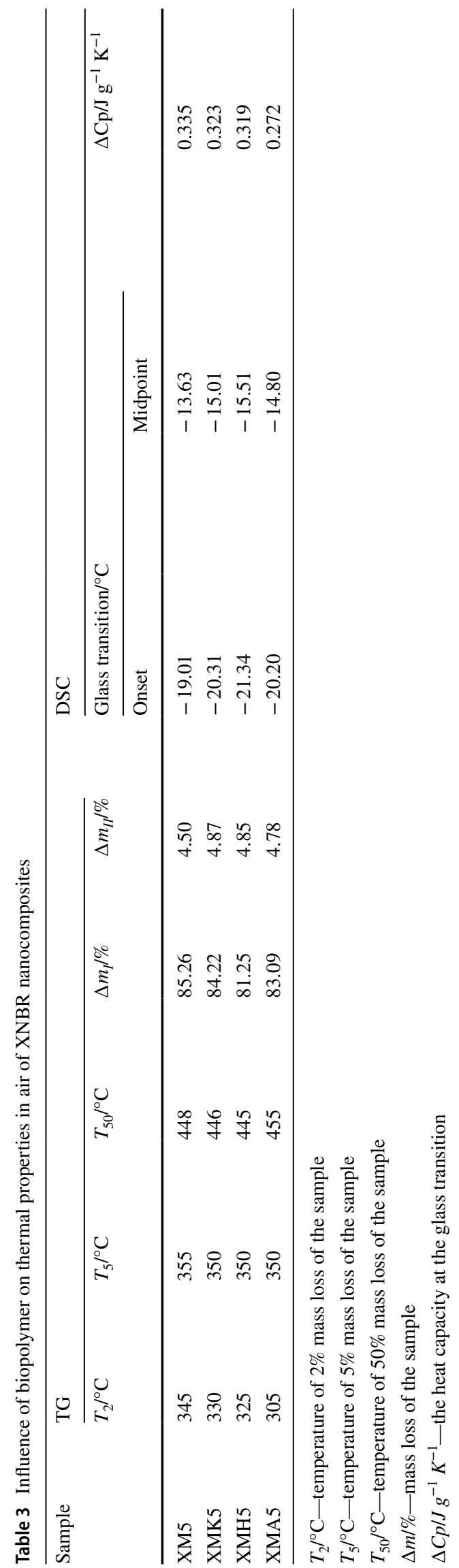

aging procedure. The aging coefficient $S$ was determined from the following relationship (2):

$S=\left[\mathrm{TS}_{\mathrm{b} 1} \cdot E_{\mathrm{b} 1}\right] /\left[\mathrm{TS}_{\mathrm{b} 2} \cdot E_{\mathrm{b} 2}\right]$

where $\mathrm{TS}_{\mathrm{b} 1}$ and $E_{\mathrm{b} 1}$-tensile strength and elongation at break after thermal aging, $\mathrm{TS}_{\mathrm{b} 2}$ and $E_{\mathrm{b} 2}$ - tensile strength and elongation at break before thermal aging, respectively.

The changes in color has been assessed using a CM-3600d KONICA MINOLTA, spectrophotometer, United Kingdom UK. The change of color was examined after thermo-oxidative aging process and soil test. The tests were visualized using the $\mathrm{dE}^{*} \mathrm{ab}$ parameters and reflectometric spectra.

Biodecomposition of rubber, performed in soil (soil tests) — samples; paddle-shaped with the dimensions $7.5 \mathrm{~cm}$ by $1.25 \mathrm{~cm}$, and the sampling of $0.4 \mathrm{~cm}$; were placed in an active universal soil $(10 \mathrm{~cm})$ and incubated at a temperature of $30^{\circ} \mathrm{C}$ and $80 \%$ RH. After one, two and three months of incubation in a climatic chamber MEMMERT HPP 108 (Memmert GmbH, Germany), the appearance of samples was evaluated using microscopy. Tests were carried out according to the standard PN-EN ISO 846, December 2002.

SEM photographs were taken to identify structural changes in the obtained composites by scanning electron microscopy SEM, Baldek SCD095 (Sputter Coaded) LEO 1530 (Zeiss, Switzerland); Institute of High Pressure Physics, Polish Academy of Sciences, Poland.

\section{Results and discussion}

\section{Rheological: mechanical analysis}

The table below (Table 2) presents rheological-mechanical properties of XNBR composite containing keratin, its hydrolyzate and condensate with the addition of 5 or 10 parts by mass of montmorillonite based on 100 parts by mass of rubber.

The addition of keratin and modification of keratin resulted in an increase in the minimum torque values, $L_{\mathrm{L}}$ and therefore increased the viscosity of the XNBR rubber, regardless of whether 5 or 10 parts by mass of montmorillonite were incorporated.

The value of increment in torque, $\Delta L$, connected with the yield of blend cross-linking, is clearly higher in the case of all the blends containing keratin, hydrolyzate and condensate. However, the cure time and curing time are reduced compared to the native sample. It is worth emphasizing the increase in mechanical strength parameter for samples containing the hydrolyzate and condensate of keratin. This parameter $\left(\mathrm{TS}_{\mathrm{b}}\right)$ increased nearly by seventeen percent especially for XMH5 and XMA5 materials. 

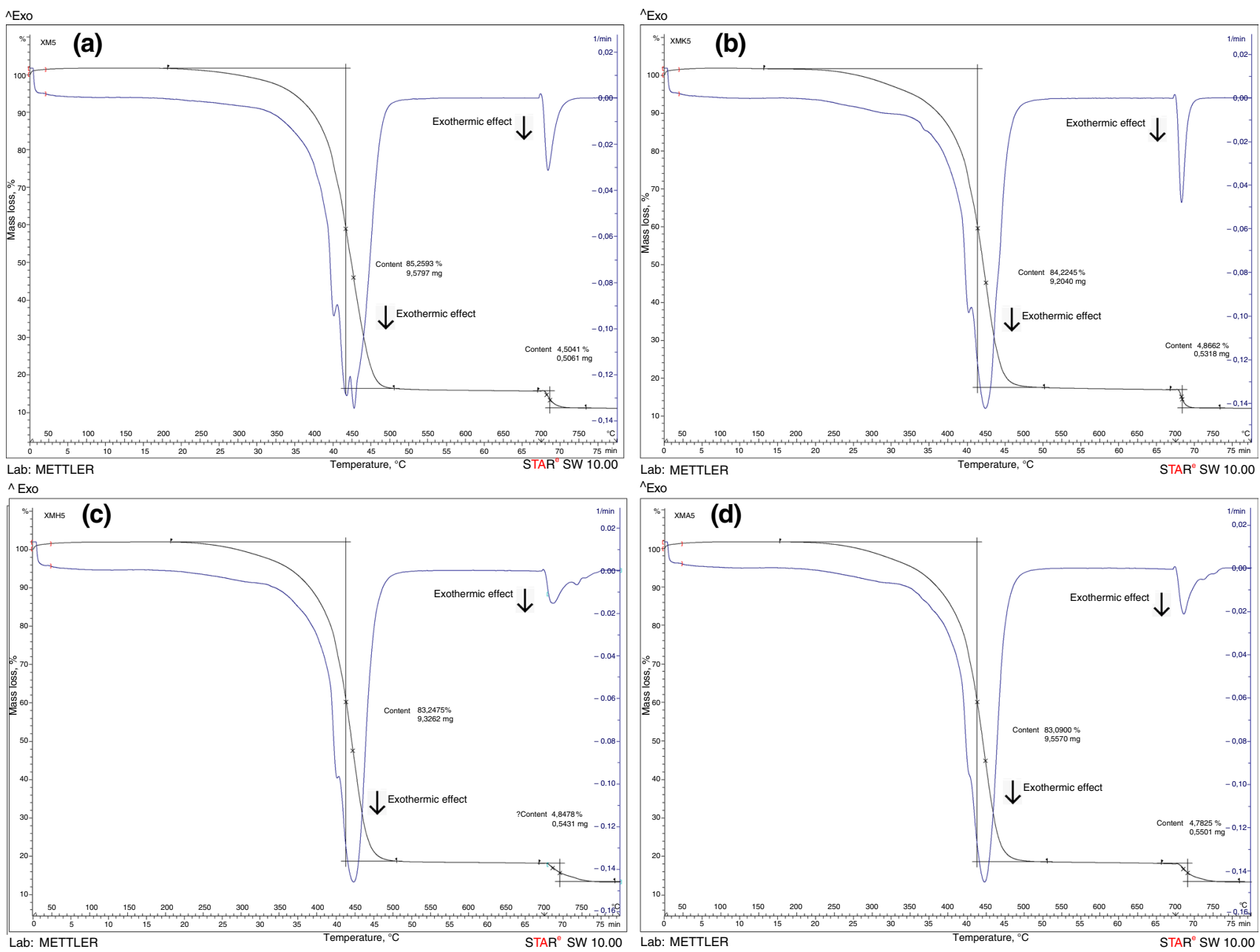

Fig. 3 Influence of keratin modifications on the TG-DTG of XNBR nanocomposities. XM5 (a); XMK5 (b), XMH5 (c) and XMA5 (d)

After adding keratin and its modifications, the structure of the elastomer network changed, and hardness values were increased even up to $40 \%$. The introduction of 5 and 10 parts by mass of the layered silicate increased the hardness values relatively to the standard samples.

\section{Thermal analysis}

In addition to mechanical properties, processing properties of composites are also very important. Much better dispersion of components, more favorable and even distribution of them, is observed when applying 5 parts by mass of montmorillonite, hence for these studies, among others, these compounds were selected for further studies. The test method is based on a thermal analysis in which the difference in energy supplied to the test substance and formula is measured as a function of temperature or time. Table 3 shows the results of thermal properties, thermal stability of vulcanizates determined by the temperature value for loss of mass of two, five and fifty percent, which decreases due to the introduction of keratin, keratin enzymatic hydrolyzate and keratin condensate.

The above table shows that the temperature values of 2 , $5 \%$ and $50 \%$ of the mass loss of the sample, $T_{2}, T_{5}, T_{50}$, respectively, are higher for the XM5 composite. This means that the degradation of samples containing keratin modifications starts earlier and is therefore faster than the degradation of the unfilled sample. This is in line with the studies on biological-thermal aging presented in the next analysis.

The preferred factor is the reduction of the mass loss $(\Delta m / \%)$ of the materials tested. Lower values of total sample mass loss with biological additives compared to the standard are due to slower oxidation processes and chemical degradation under non-aged conditions.

Two loss domains are observed on all four thermal curves (Fig. 3) - two exothermic peaks. The first peak of high intensity indicates mass loss during the crystallization process 


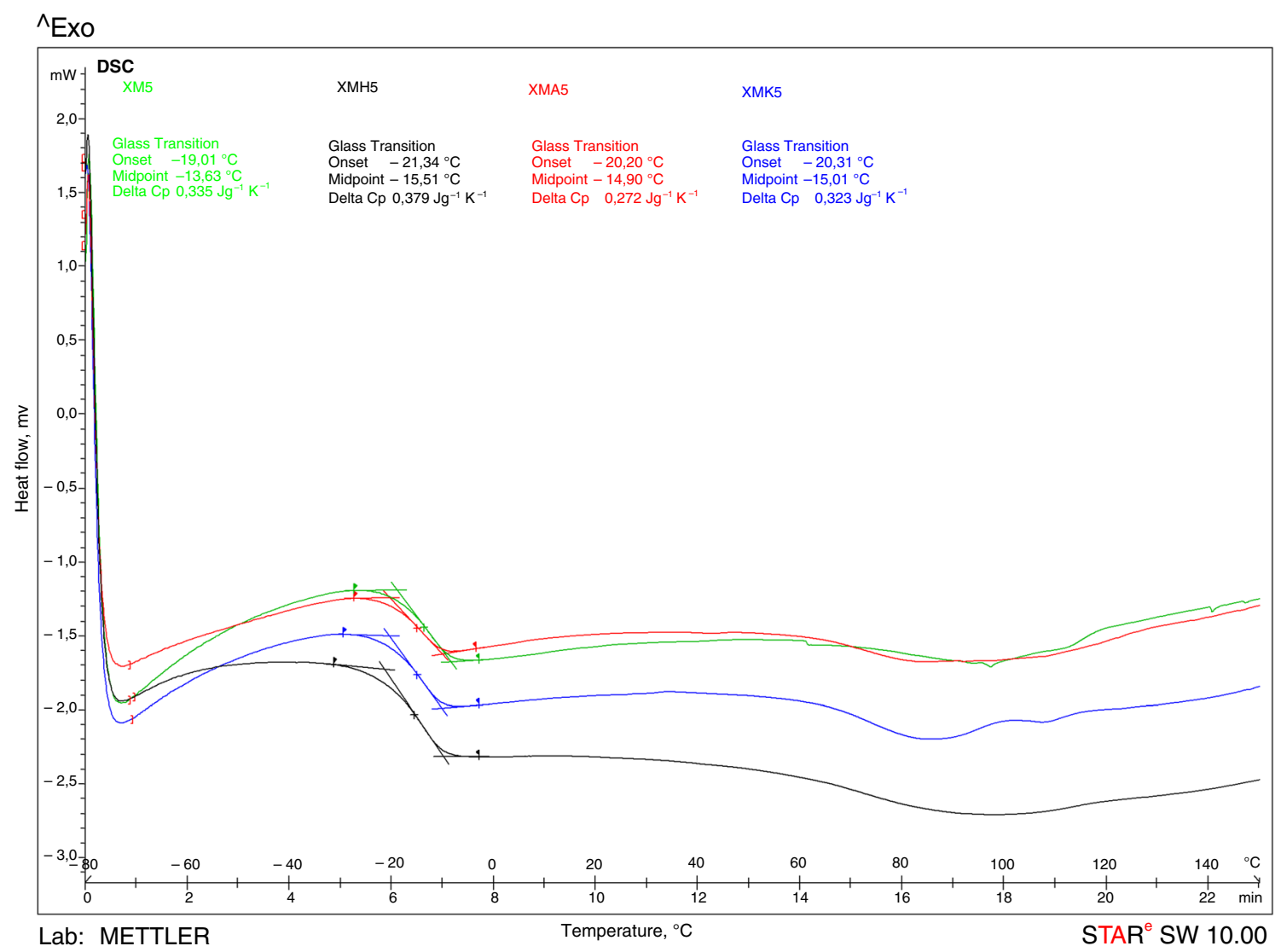

Fig. 4 Influence of keratin modifications on the DSC of XNBR nanocomposities. XM5 (a); XMK5 (b), XMH5 (c) and XMA5 (d); combination of DSC curves

and can be attributed to the degradation of the composite substrate-it is seen on all four curves at a temperature of about $450{ }^{\circ} \mathrm{C}$. In contrast, the second domain $\left(T=720^{\circ} \mathrm{C}\right)$ is probably associated with crystallization processes and simultaneous degradation of the keratin modifications used. The percentage residue after the row is the largest for the keratin used and decreases from the hydrolyzate to the adduct relative to the standard.

DSC analysis shows that the elasticity of the sample increases slightly when adding keratin modifications (reduced glass transition temperature $T_{\mathrm{g}}$, e.g. -20 to $-21{ }^{\circ} \mathrm{C}$ ). This is probably due to the interaction between the components contained in the elastomer matrix. The result is an increasing mobility of the segments in the contact phase, which in turn causes the $T_{\mathrm{g}}$ values to shift toward lower temperatures. This can be compounded by the effect of water loss, which is inside the keratin structure. The water is occluded due to physical influences.

The thermal effect $(\triangle \mathrm{Cp})$ is balanced to be more costeffective for samples with natural fillers. It has been found that the use of biopolymers reduces the amount of heat generated in the vulcanization process.
On the TG curves (Fig. 3), the change in the type of filling starting from keratin, its hydrolyzate to the keratin condensate does not change the position of the distribution peaks. Differences in the degree of conversion and chemical composition are also reflected in the mechanical properties of the presented composites.

The quasi-linear portions of the DSC curve before and after the degree of conversion show the temperature of the extrapolated peak start for unfilled composite with the value of $63{ }^{\circ} \mathrm{C}$ (onset) whose extrapolated end falls at $118{ }^{\circ} \mathrm{C}$ (endset) (Figs. 3-5). After the introduction of the modified biopolymers, these transformations are shifted toward lower temperatures, XMK5 $\left(61 / 111{ }^{\circ} \mathrm{C}\right)$, respectively (Fig. 5 B); XMH5 $\left(54 / 139{ }^{\circ} \mathrm{C}\right)$ (Fig. 5c); XMA5 (59/101 $\left.{ }^{\circ} \mathrm{C}\right)$ (Fig. 5d). The nanocomposite containing the keratin hydrolyzate is slightly different, because the phase transition ends at a higher temperature $\left(138^{\circ} \mathrm{C}-\right.$ Fig. $\left.5 \mathrm{c}\right)$. The change may be due to the evaporation of physically bound water with the keratin hydrolyzate. The highest hygroscopicity is precisely the keratin hydrolyzate due to the presence of polar groups (COO-, $-\mathrm{NH}_{2}, \mathrm{NH}_{3}^{+}$, etc.) in contrast to the keratin itself or the hydrophobized condensate of keratin containing stearin chains in its structure. 

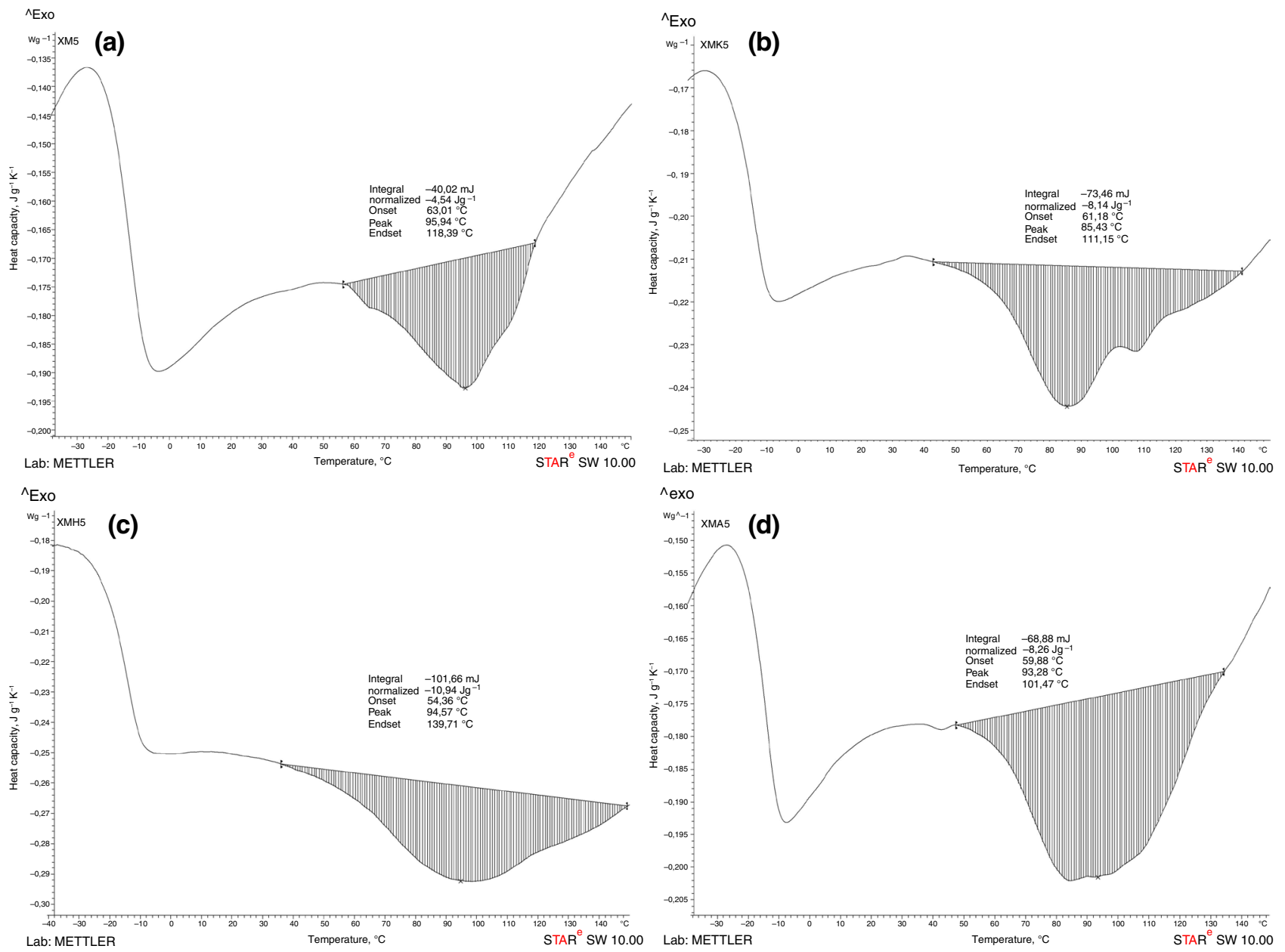

Fig. 5 Influence of keratin modifications on the DSC XNBR nanocomposities. XM5 (a); XMK5 (b), XMH5 (c) and XMA5 (d)

The difference in specific heat before and after transformation is proportional to conversion; hence, we can see in Fig. 5 that the total thermal effect visible with wide exothermic peaks gives $-40 \mathrm{~mJ}$ for the standard, respectively, and for nanocomposites with biopolymers above $-68 \mathrm{~mJ}$ (XMK5); -73 mJ (XNH5); - $101 \mathrm{~mJ}$ (XMA5). The presence of biopolymers caused a reduction in the thermal crosslinking efficiency of the elastomer.

The analysis of the results presented in Table 4 leads to the conclusion that the XNBR elastomer addition of biopolymers significantly limits the inflammability of XNBR vulcanizates, as evidenced by both longer combustion time in air $(\mathrm{t}, \mathrm{s})$ and higher oxygen index (OI,-). The limited flammability of the elastomeric materials produced is the result of probably a lower rate of thermal decomposition processes of the tested vulcanizates and a larger residue after this process (mass loss, $\Delta \mathrm{m} / \%$ ), as well as nitrogen emissions released from biopolymers during decomposition processes. Nitrogen belongs to the group of flame-retardant gases, which significantly reduces the reactions of free radicals in the air, thus reducing the diffusion of oxygen to the flame zone. The reduction of combustibility of the obtained nanocomposites may also be associated with the nanometric size of the modified keratin particles [14, 29].

Regardless of the type of filler used, the flash-point temperature (FPT) of the filled XNBR rubber vulcanizate increases, which is a sign that the flame retention of the obtained nanocomposites is reduced. The use of 10 parts by mass of MMT versus $5 \mathrm{phr}$, increased the combustion time of the samples relative to XM10 and resulted in a slight reduction in the flash point.

\section{Bio-thermal aging analysis}

Keratin is a protein with a high content of amino acid cysteine. The oxidation of SH groups (formed by hydrolysis of keratin) can result in the formation of stabilizing 
Fig. 6 The effect of keratin and its modification for percentage change of thermo-oxidative aging factor $(S ;-)$ XNBR vulcanizates with $5 \mathrm{phr}(\mathbf{a})$ and $10 \mathrm{phr}$ (b) of montmorillonite. The reflectometric spectra of XM5 (c) and XMA5 (d) XNBR composites after a 90-day biodecomposition process (3 months)
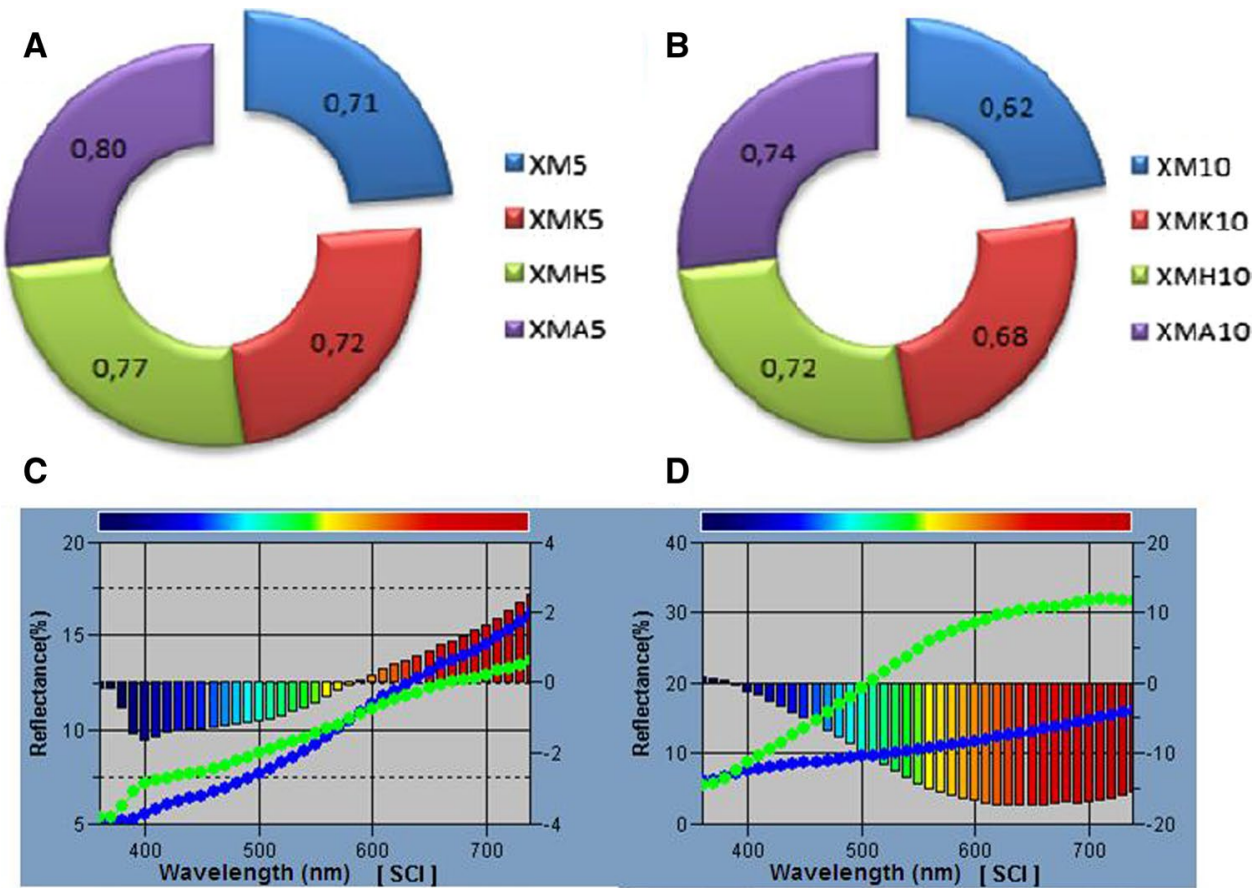

-SO* radicals, whereby the enzymatic hydrolyzate of keratin shows antioxidant properties. Therefore, the application of bioadditives act as inhibitors of thermo-oxidative aging (Fig. 6a, b). Due to the different structure of the keratin structure, the enzymatic keratin hydrolyzate and the enzyme keratin hydrolyzate condensate, they influence the resistance to thermo-oxidative aging in a different way-parameter $S$.

Montmorillonite as a mineral clay among many advantages also has a disadvantage in this case, i.e., the ability to absorb the ion, to exchange them with aqueous solu- should be performed in the future in order to obtain a homogeneous polymer composite.

Reflectometric spectra of selected vulcanizates are shown in the following Fig. 6c, d.

Reflectometric spectra show differences in the changes of color of each vulcanizate subjected to biodegradation process.

In the case of vulcanizate with biofuel and montmorillonite additive the color coefficients are the highest, which means that the sample has worse protection against color
Table 4 Flammability of XNBR nanocomposities

\begin{tabular}{lllllllll}
\hline Composites & XM5 & XMK5 & XMH5 & XMA5 & XM10 & XMK10 & XMH10 & XMA10 \\
\hline Time of burning samples/s & 288 & 285 & 290 & 312 & 273 & 386 & 338 & 379 \\
OI-oxygen index/- & 0.220 & 0.225 & 0.232 & 0.228 & 0.190 & 0.201 & 0.216 & 0.220 \\
Flash-point $/{ }^{\circ} \mathrm{C}$ & 330 & 332 & 335 & 332 & 344 & 343 & 346 & 347 \\
\hline
\end{tabular}

tions. Therefore, the introduction of 10 parts is less preferred than 5 parts by mass and reduces the aging factor (S/-) of the elastomer test composites. Montmorillonite has mineral water layers and has the ability to both adsorb and absorb water molecules, which is manifested by material swelling or change of network gaps. The processes of water loss or absorption take place continuously; therefore, MMT drying eliminates about $15 \%$ of water and reduces the distances in cell monolayers. The silicate exhibits a hydrophilic character, so in this case, when introducing into the elastomeric matrix, the silicate modification change than the XM5 sample.

In order to assess the changes that have occurred in the appearance of the tested vulcanizates, pictures were taken with an optical microscope after the biodecomposition process of materials as well as before the biodegradation processes. As a result of the biodegradation process, XNBR vulcanizates containing biopolymers show a clear change in color on the surface and a change of the structure of materials, as used fillers decompose in the soil (Fig. 7a). Tests were conducted for composites incubated during 1,2 and 3 months. The changes seen in the pictures are the result of the biotic factors which modified proteins in the studied 
Fig. 7 Biodecomposition process of composites XM5, XMK5 and XMA10 (a) during a three-month incubation in soil tests; the effect of keratin addition to the time-evolution of biodecomposition as revealed in the variation of the tensile strength $\Delta \mathrm{TSb}, \%$ for XM5 and XMK5 materials (b)
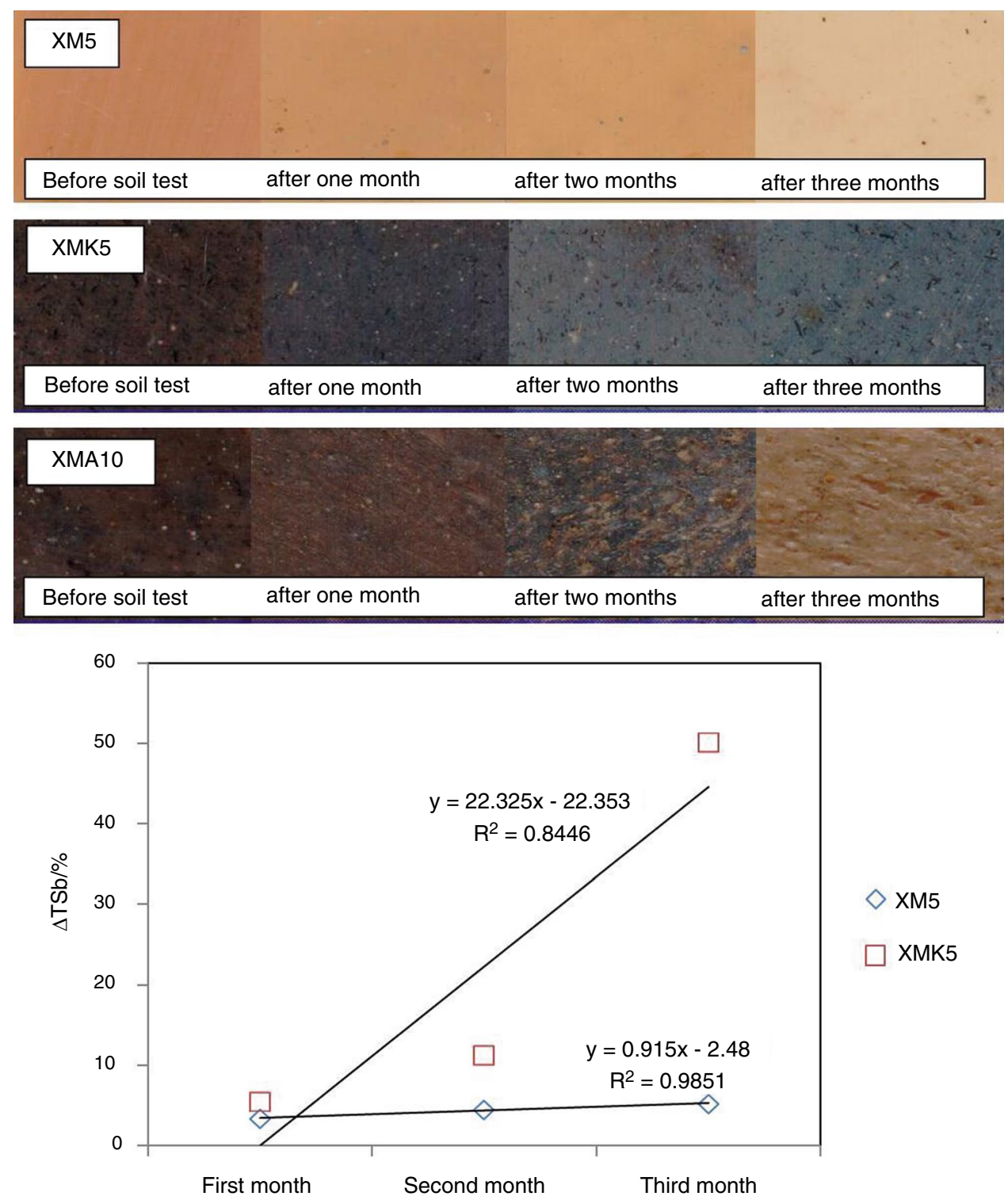

vulcanizates during incubation in universal soil. The greatest change in the appearance of the samples tested was observed for the vulcanizates containing the condensate of keratin (bubbles, deformation, cracks, micropores).

On the basis of the regression curve (Fig. 7b), the dependence of flax in the XM5 composition is visible- the regression coefficient close to unity, the natomiaast for the filled nanocomposite the change in the value of mechanical moultiness in time undergoes significant increase, nonlinear for XMK5.

The regression coefficient $\left(R^{2}\right.$ determination) indicates a better adjustment of the regression function to the empirical data for the XM5 composite; however, the value of 0.84 is also close to unity for XMK5.

To confirm the occurring degradation processes in the environment, the mechanical parameters of the tested composites after this process were checked.
Minor changes are observed for the reference vulcanisate after a three-month incubation, whereas for material containing 5 parts by mass of keratin the deterioration of the tensile strength was by 50 percent (accurately $50.15 \%$ ).

\section{Conclusions}

In our research, we managed to obtain composites with satisfactory mechanical properties, and thanks to the use of a modified keratin to the XNBR elastomer, the rheological and mechanical properties, the density of cross-linking were improved, and resistance to thermo-oxidative aging was also improved.

The fillers should most preferably be applied in the form of enzymatically hydrolyzed keratin and its condensate with 
technical stearin. The incorporation of montmorillonite is advantageous in an amount of 5 parts by mass than $10 \mathrm{phr}$ in combination with a modified animal protein, e.g., due to deterioration of the thermal stability of the composites $(S /-)$. As a result of the application of modified keratin into the XNBR elastomer, rheological properties, mechanical, cross-link density, increased resistance to thermo-oxidative aging are improved. The incorporation of biopolymers and montmorillonite into the elastomeric matrix did not significantly improve the thermal stability of the XNBR vulcanizates, but the overall mass loss of the sample is lower compared to the reference sample. Slight changes in glass transition parameters indicate increased flexibility of macromolecules structure mixed with a natural filler. This fact is confirmed by higher values of minimum torque moment of XMK5, XMH5, XMA5 samples over an unfilled composite (rheometric tests). Soil testing and color change confirm the increased susceptibility of protein-containing composites to biodegradation processes, and at the same time show the slow disappearance of the biotic factor, which is the protein in the XNBR elastomer structure during simulated accelerated degradation processes.

Open Access This article is licensed under a Creative Commons Attribution 4.0 International License, which permits use, sharing, adaptation, distribution and reproduction in any medium or format, as long as you give appropriate credit to the original author(s) and the source, provide a link to the Creative Commons licence, and indicate if changes were made. The images or other third party material in this article are included in the article's Creative Commons licence, unless indicated otherwise in a credit line to the material. If material is not included in the article's Creative Commons licence and your intended use is not permitted by statutory regulation or exceeds the permitted use, you will need to obtain permission directly from the copyright holder. To view a copy of this licence, visit http://creativecommons.org/licenses/by/4.0/.

\section{References}

1. Janowska G, Mikołajczyk T, Olejnik M. Thermal properties and flammability of fibres made from polyimidoamide nanocomposite. J Therm Anal Calorim. 2007;88:843-9. https://doi.org/10.1007/ s10973-005-7429-6

2. Janowska G, Mikołajczyk T, Boguń M. Effect of the type of nanoaddition on the thermal properties of polyacrylonitrile fibres. J Therm Anal Calorim. 2007;89:613-8.

3. Laskowska A, Zaborski M. Zastosowanie mineralnego krzemianu warstwowego w kompozytach elastomerowych. Przemysł Chemiczny. 2010;89(4):458-61.

4. Laskowska A, Lipińska M, Zaborski M. Hydrotalkit jako napełniacz karboksylowanego kauczuku butadienowo-akrylonitrylowego. Przemysł Chemcizny. 2011;90(5):878-82.

5. Prochoń M, Przepiórkowska A, Zaborski M. Keratin as a filler for carboxylated acrylonitrile-butadiene rubber XNBR. J Appl Polym Sci. 2007;106(6):3674-87. https://doi.org/10.1002/app.26324

6. Janowska G, Kucharska-Jastrzabek A, Prochon M, Przepiorkowska A. Thermal properties and combustibility of elastomerprotein composites. Part II. Composites NBR-keratin. J Therm
Anal Calorim. 2013;113:933-38. https://doi.org/10.1007/s1097 3-012-2796-2.

7. Prochoń M, Janowska G, Przepiorkowska A, Kucharska-Jastrzabek A. Thermal properties and combustibility of elastomer-protein composites. Part I. Composites SBR-keratin. J Therm Anal Calorim. 2012;109:1563-70. https://doi.org/10.1007/s 1097 3-011-2028-1.

8. Weiner A, Paprocka I, Gołebiowksa A, Kwiatek K. Food and feed hygiene. Vet Life. 2012;87(12):1035-37.

9. Prochoń M, Janowska G, Przepiórkowska A. Self-exclusion to acrylonitrile-butadiene. The mixture of acrylonitrile-butadiene rubber with improved thermal properties P-399081 Patent PL.

10. Janowska G, Kucharska-Jastrząbek A, Rybiński P. Thermal stability, combustibility and fire hazard of butadiene-acrylonitrile rubber nanocomposites. J Therm Anal Calorim. 2011;103:1039-46.

11. Rybiński P, Janowska G, Jóźwiak M, Pająk A. Thermal properties and flammability of nanocomposites based on diene rubbers and naturally occurring and activated halloysite nanotubes. J Therm Anal Calorim. 2012;107:1243-49.

12. Popescu C, Wortmann FJ. In: Proceedings of the NATAS Annal Conference on Thermal Analysis and Applications, Germany, 2006.

13. Mikołajczyk T, Szparaga G, Janowska G. Influence of silver nanoadditive amount on the supramolecular structure, porosity, and properties of polyacrylonitrile precursor fibres. Polym Adv Technol. 2009;20:1035-43.

14. Feughelman MA, Lymand DJ, Willis BK. The parallel helices of the intermediate filaments of $\alpha$-keratin. Int J Biol Macromol. 2002;30:95-6.

15. Prochoń M, Janowska G, Przepiórkowska A, KucharskaJastrząbek A. Stabilność termiczna i palność biorozkładalnych materiałów elastomerowych. Polimery. 2013;58(5):413-20.

16. Janowska G, Przygocki W, Włochowicz A. Palność Polimerów i Materiałów Polimerowych. Warszawa: WNT; 2007.

17. Madruga EL, Fernández-Garcia M, Cerrada ML. Thermal, morphological and rheologicalcharacterization of poly (acrylic acidg-styrene) amphiphilic graft copolymers. Polymer. 2005;46:2233.

18. Pat Eur GB 795582. 1958.

19. Barone JR, Schmidt WF, Liebner FE. Compounding and moulding of polyethylenecomposites reinforced with human hair fiber and its vibrational analysis. Compos Sci Technol. 2005;65:683-92.

20. Bullions TA, Hoffman D, Gillespie RA, O'Brien JP, Loos AC. Contributions of feather fibres and various cellulose fibres to the mechanical properties of polypropylene matrix com-posites. Compos Sci Technol. 2006;66:102-14.

21. Katoh K, Shibayama M, Tanabe T, Yamauchi K. Preparation and physicochemical properties of compression-molded keratin films. Biomaterials. 2004;25:2265-72.

22. Przepiórkowska A, Chrońska K, Prochoń M. Biodegradable elastomeric vulcanizates. Rubber Chem Technol. 2008;81:723-35.

23. Abad LV, Relleve LS, Aranilla CT, Aliganga AK, San Diego CM, dela Rosa AM. Natural rubber latex natural anti-oxidants for radiation vulcanized. Polym Degrad Stab. 2002;76:275-9.

24. Martinez-Hernandez AL, Velasco-Santos C, de Icaza M, Castano VM. Dynamical-mechanical and thermal analysis of polymeric composites reinforced with keratin biofibers from chicken feathers. Compos Part B. 2007;38:405-10.

25. Fukushima Y, Mori K, Murase A. Application of intercalated compound of montmorillonite and $N, N$ '-diphenyl-p-phenylenediamine to antioxidant for rubber materials. J Incl Phenom. 1984;2:305-15.

26. Hongmei DU, Zengzhi Z, Miaomiao WU, Jin Z. Water-conducting characteristics and micro-dynamic self-adjusting behavior of polyacrylamide/montmorillonite coating. J Wuhan Univ Technol Mater. 2015;30:1191-97. https://doi.org/10.1007/s1159 5-015-1294-3. 
27. Janowska G, Kucharska-Jastrząbek A, Rybiński P. Thermal stability, flammability and fire hazard of butadiene-acrylonitrile rubber nanocomposites. J Therm Anal Calorim. 2011;103(3):1039-46.

28. Prochoń M, Tshela-Ntumba Y-H. The effect of modified biopolymers and poly(vinyl alcohol) on carboxylated acrylonitrile-butadiene rubber properties. Polimery. 2015;7(8):508-15.

29. Prochoń M, Przepiórkowska A, Zaborski M. Elastomer - keratin composites. Kautschuk und Gummi Kunststoffe. 2006;10:520-25.
Publisher's Note Springer Nature remains neutral with regard to jurisdictional claims in published maps and institutional affiliations. 